\title{
Ultrastructural pathology of primary ciliary dyskinesia: report about 125 cases in Germany
}

\author{
Dirk Theegarten $^{1^{*}}$ and Michael Ebsen ${ }^{2}$
}

\begin{abstract}
Background: Primary ciliary dyskinesia (PCD) is a rare genetically induced disorder of cilia inducing mainly respiratory diseases. Transmission electron microscopy (TEM) analysis of ciliary ultrastructure is classically used for diagnosis. We report our experience of TEM investigations in a large series of patients.

Methods: TEM analysis performed of 742 biopsies from patients with suspected PCD was reviewed retrospectively. Ultrastructural defects were analysized further in 125 cases with changes typical for PCD.

Results: In $18.1 \%$ of patients diagnosis of PCD was made because of morphological alterations, in $68.2 \%$ secondary changes were seen. In 13.7\% material was not feasible for analysis. Mostly defects of dynein arms were detected in PCD (96.8\%). In particular defects of the inner arms (51.2\%) and combined dynein defects (37.6\%) were found. Total loss of dynein arms was dominant. Only in $3.2 \%$ deficiencies of central structures were found alone. Associated situs inversus or dextracardia was reported clinically in $21.4 \%$.
\end{abstract}

Conclusions: TEM analysis is possible in most patients and a useful tool for diagnosis of PCD. Functional and genetic analysis should be done additionally. Registers should be installed to collect all available informations and push further research.

Virtual Slides: The virtual slide(s) for this article can be found here: http://www.diagnosticpathology.diagnomx.eu/ vs/1629267757580889.

\section{Background}

Cilia are ancient evolutionarily conserved organelles that typically project from the apical surface of cells. Their biological roles include whole-cell locomotion, movement of fluid, chemo-, mechano- and photosensation and sexual reproduction. Defects in cilia are associated with a growing number and wide range of human diseases, which in the whole are called ciliopathies [1].

Historically the disease has been described as immotile cilia syndrome by BA Afzelius [2]. Primary ciliary dyskinesia (PCD) is a predominantly autosomal recessive inherited disorder. Estimation of prevalence is difficult and given between 1:10,000 to 40,000 live births [3,4]. Recurrent and chronic upper and lower respiratory tract infections, and in 40-50\% of cases, mirror-image organ arrangement and other forms of heterotaxy are main symptoms [4-6]. Symptoms vary according to the age in

\footnotetext{
* Correspondence: dirk.theegarten@uk-essen.de

1 Institute of Pathology and Neuropathology, University Hospital Essen,

University of Duisburg-Essen, Hufelandstrasse 55, 45147 Essen, Germany

Full list of author information is available at the end of the article
}

which diagnosis is made. Diagnosis of PCD requires the presence of the characteristic clinical phenotype and either specific ultrastructural ciliary defects identified by TEM or abnormal ciliary function [3-6]. In a few cases only abnormal function is found aloneside with normal ultrastructure, therefore analysis of ciliary function and TEM are recommended. Guidelines and algorithms have been developed to standardize diagnostic procedures $[4,7]$. Diagnostic modalities will vary in different countries. A recent questionnaire survey of the European Respiratory Society in Austria reported that TEM analysis was done in $73 \%$ of all PCD patients [8].

The axoneme of motile cilia is composed of nine peripheral doublet microtubules with attached outer and inner dynein arms (ODA and IDA, respectively) and radial spokes, surrounding a central complex (CC) with two central microtubules and the central sheath (so called $9+2$ tubulus structure) [1]. Cilia consist of over 250 various proteins, making a broad spectrum of defects possible. Genes involved in PCD have been characterized, but not all cases can be described genetically
C Biomed Central 
[4]. PCD seems to be linked with malfunctioning in adenosine triphosphate metabolism $[9,10]$. In TEM analysis different defects are seen in PCD, but only some larger series describing these defects exist [11-18]. Sometimes only case reports are given $[9,19]$. Therefore we reviewed our cases with ultrastructural diagnosis of PCD retrospectively to compare the results with other studies.

\section{Methods}

All specimens sent to the Institutes of Pathology in Bochum (2002-2006), Essen and Kiel (2006-2009) for TEM analysis because of suspected PCD were analysed retrospectively. Specimens were taken by paediatrics or respiratory physicians and obtained from nasal or tracheobronchial mucosa. Brushings or biopsies were immersed in buffered 2.5\% glutaraldehyde and processed as usually [20]. Semithin sections were done for prior selection of suitable blocks. Ultrathin sections were examined at at least 60,000 fold magnification. In each case at least 50 transverse ciliary sections of different cells were investigated. Ciliary abnormalities in over $20 \%$ of available axonema were required for diagnosis of primary defects. Ultrastructural defects of dynein arms were divided in cases with total loss or rudimental structure of IDA or ODA.

\section{Results}

\section{TEM feasibility}

Totally 742 specimens were analysed. 102 (13.7\%) of these were not suitable for further investigations. In 95.1\% no cilia were found at all (in $11.8 \%$ metaplasia, in $5.9 \%$ no material), and in $4.9 \%$ only a few cells with cilia were seen, In 506 (68\%) cases only secondary changes due to respiratory infections were detected. Secondary changes were seen in a variable extend and consisted of plebs, numerical aberrations of microtubuli in some cilia, and compound cilia. But in 16 (3.2\%) of these cases situs inversus, Kartagener Syndrome or dextrocardia was reported clinically. In $11.1 \%$ of the specimens a repeated investigation was recommended because only a relatively small number of cilia were seen. In 134 (18\%) cases primary changes were found, ultrastructural defects were documented in detail in 125 patients. Mostly nasal brushings were presented (64\%).

\section{Geographics}

Brushings or specimens were recruited from patients who were visiting paediatrics or respiratory physicians in different states in Germany. Most cases of PCD ( $\mathrm{n}=$ 125) were diagnosed in Northrhine-Westphalia (60.8\%). Others were found in Schleswig-Holstein (11.2\%), Lower Saxony (8.8\%), Hesse (8.8\%), Berlin (4.8\%), Baden-Württemberg (2.4\%), Bremen (1.6\%), Hamburg $(0.8 \%)$, and Rhineland-Palatinate $(0.8 \%)$.

\section{Clinical features in PCD}

Median of age in PCD was 7.7 (range: 0.1 - 50) years. $59.2 \%$ of patients were male, $40.8 \%$ female. According to clinical informations given together with the specimens in $103(82.4 \%)$ cases chronic infections (upper and lower respiratory tract or otitis) were dominant (85.4\%). In 22 (21.4\%) patients situs inversus or dextrocardia was reported. Results of ciliary motility analysis were communicated in $34(27.2 \%)$ cases, abnormal findings were dominant (85.3\%). Additional surgical interventions were done in three patients (two middle lobe resections because of destroyed lobe, one double lung transplantation because of bronchiectasis).

\section{Ultrastructural defects in PCD}

In $96.8 \%$ defects of dynein arms (DA) were seen (Table $1)$. Defects of the inner dynein arms (IDA) were dominant $(92 \%)$. Isolated defects of the IDA were found in 51.2\% [Figure 1, 2]. Combined IDA and outer dynein arm (ODA) defects were detected in 37.8\% [Figure 3]. Isolated defects of the ODA were only seen in 6 cases (4.8\%) [Figure 4]. Total loss of the DA was dominant, rudimentary structures were detected less frequently (Table 2). Complete missing was found in $75.2 \%$ (IDA) vs. $66.6 \%$ (ODA).

Only in 4 cases $(3.2 \%)$ deficiencies of central structures were found alone [Figure 5,6A]. In all of these the central tubulus pair was missing, in one case additionally radial spokes were not seen. A combination of DA and central defects was seen in 4 cases, in 2 cases three different defects were combined [Figure 6B].

In ten cases (8\%) diagnosis of probable PCD was made, because of the limited number of cilia detectable in ultrathin sections. Secondary changes were often seen additionally [Figure 2]. Mostly plebs, loss of one outer membrane, compound cilia and microtubular defects were found.

\section{Table 1 Ultrastructural defects in PCD}

\begin{tabular}{lll}
\hline Ultrastructural defect(s) & $\begin{array}{l}\text { numbers }(\mathbf{n}= \\
\text { 125) }\end{array}$ & percentage \\
\hline Inner dynein arms & 64 & 51.2 \\
Outer and inner dynein arms & 47 & 37.8 \\
Outer dynein arms & 6 & 4.8 \\
Central tubuli & 2 & 1.6 \\
Outer and inner dynein arms and radial & 2 & 1.6 \\
spokes & 1 & 0.8 \\
Central double tubuli & 1 & 0.8 \\
Outer and inner dynein arms and & & 0.8 \\
central tubuli & 1 & 0.8 \\
Central tubuli and radial spokes & 1 & \\
Inner dynein arms and tubuli & & \\
\hline
\end{tabular}

Mainly defects of inner and outer dynein arms are seen. 


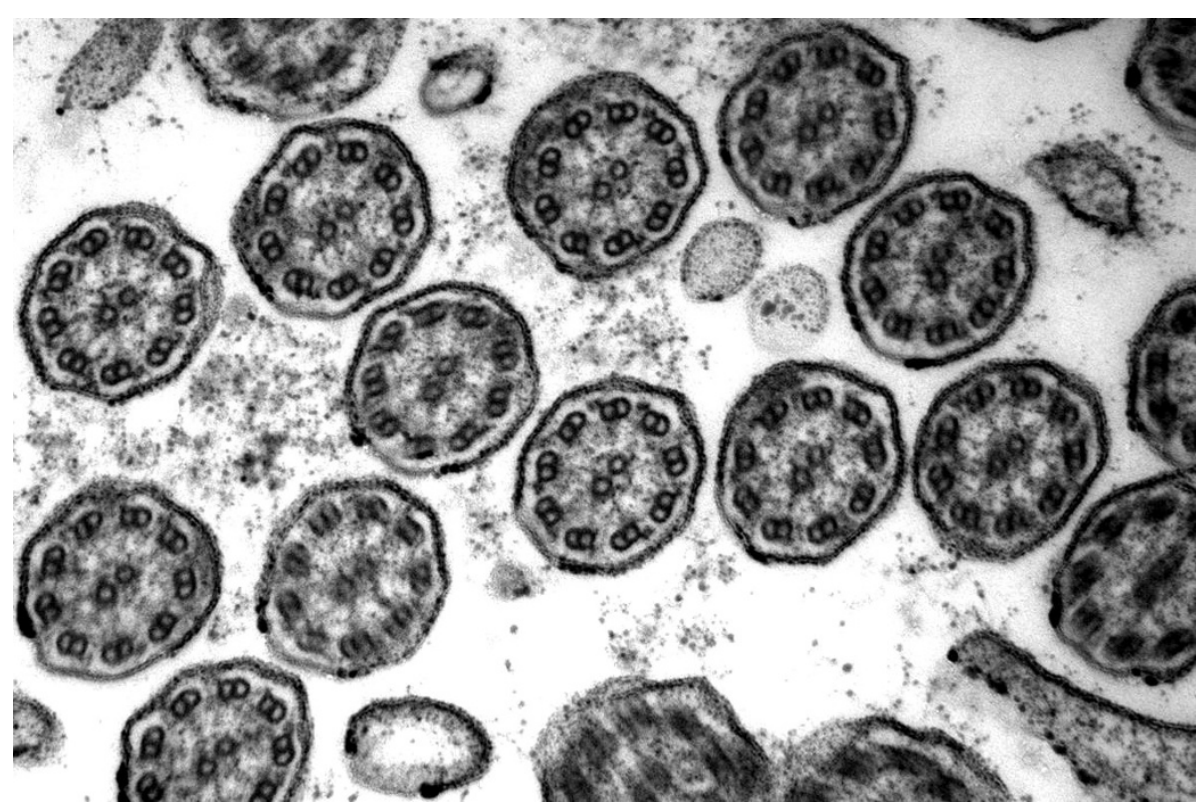

Figure 1 Defect of inner dynein arms. Loss of inner dynein arms is the ultrastuctural alteration mostly seen (original magnification $\times 85,000$ ).

\section{Discussion}

PCD is a rare genetic disease, therefore only some studies with a larger number of patients exist. In our study material was not feasible for analysis in $13.7 \%$. Papon et al. [18] report a much more higher rate of $28.6 \%$. Feasibility can be improved by using fluorescence bronchoscopy, but in pediatrics mostly unaimed brushings are taken. Some studies with a smaller number of cases ( $\leq 25)$ show difficulties to find ultrastructural defects (no dynein arm defects in 42.9\%) in PCD [21] or a high percentage $(41.2 \%)$ of only possible PCD cases [22]. In the largest study ( $\mathrm{n}=245 \mathrm{PCD}$ cases $)$ the rate of questionable defects was only 3.3\% [18]. Ten cases $(8 \%)$ in our study were classified as probable PCD because of the limited number of detectable cilia. Our results on TEM diagnosis of PCD base on own

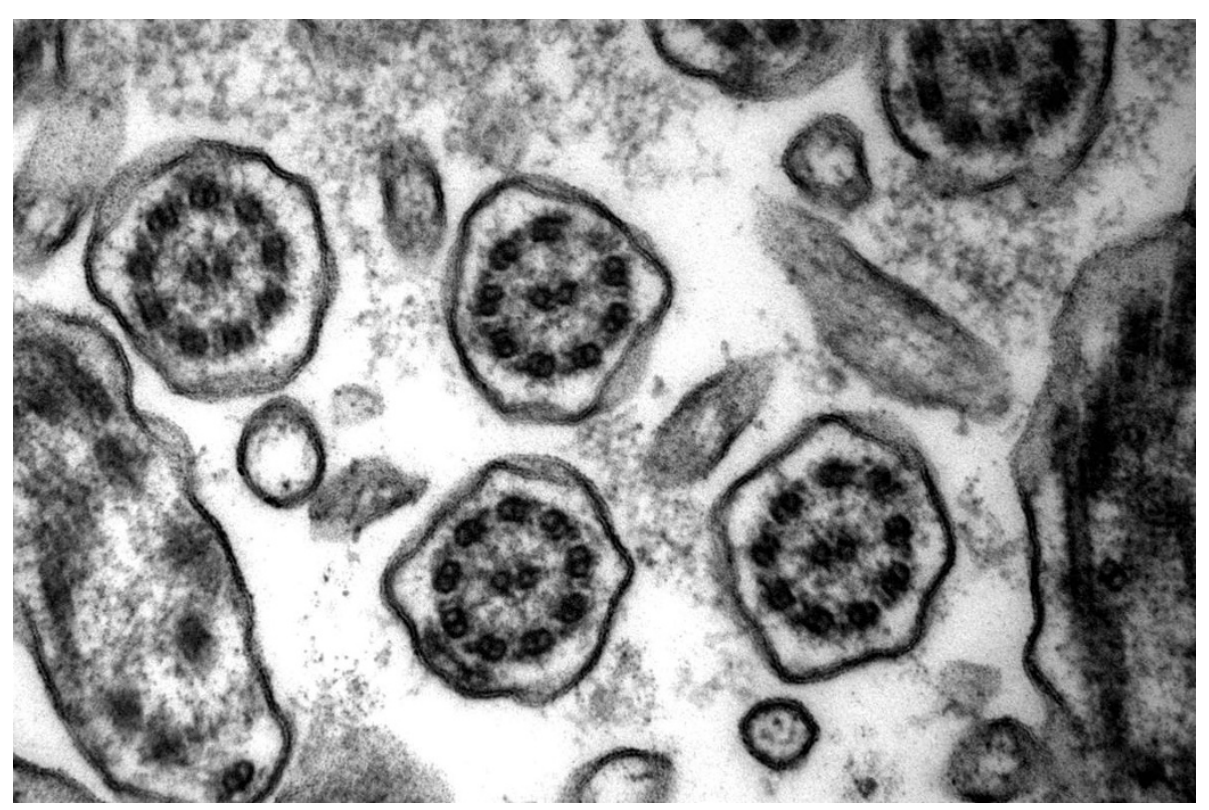

Figure 2 Defect of inner dynein arms and secondary changes. Secondary changes with compound cilia (left and right) and plebs are often found in variable extends (original magnification $\times 85,000$ ). 


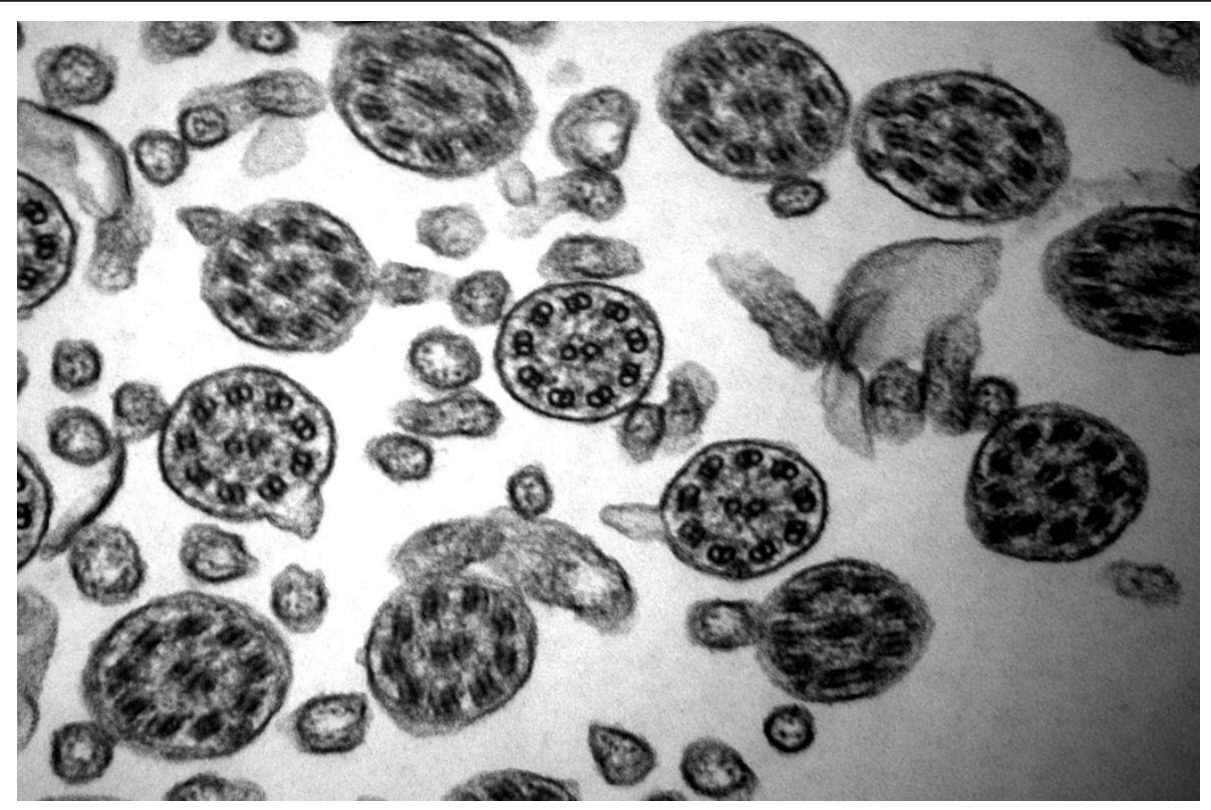

Figure 3 Defect of outer and inner dynein arms. Combined defects of outer and inner dynein arms is the lesion on the second place (original magnification $\times 85,000$ ).

ultrastructural investigations and clinical informations given with the specimens. Review of clinical records was not possible, this may explain the mismatches with the literature concerning the percentage of cases with situs inversus, which was relatively low [see Additional file 1].
Gender differences do not seem to exist, although a small male predominance was seen in our study. Studies of PCD are all covering a geographical region or country, which may also reflect a special genetic background with different results [see Additional file 1]. In studies

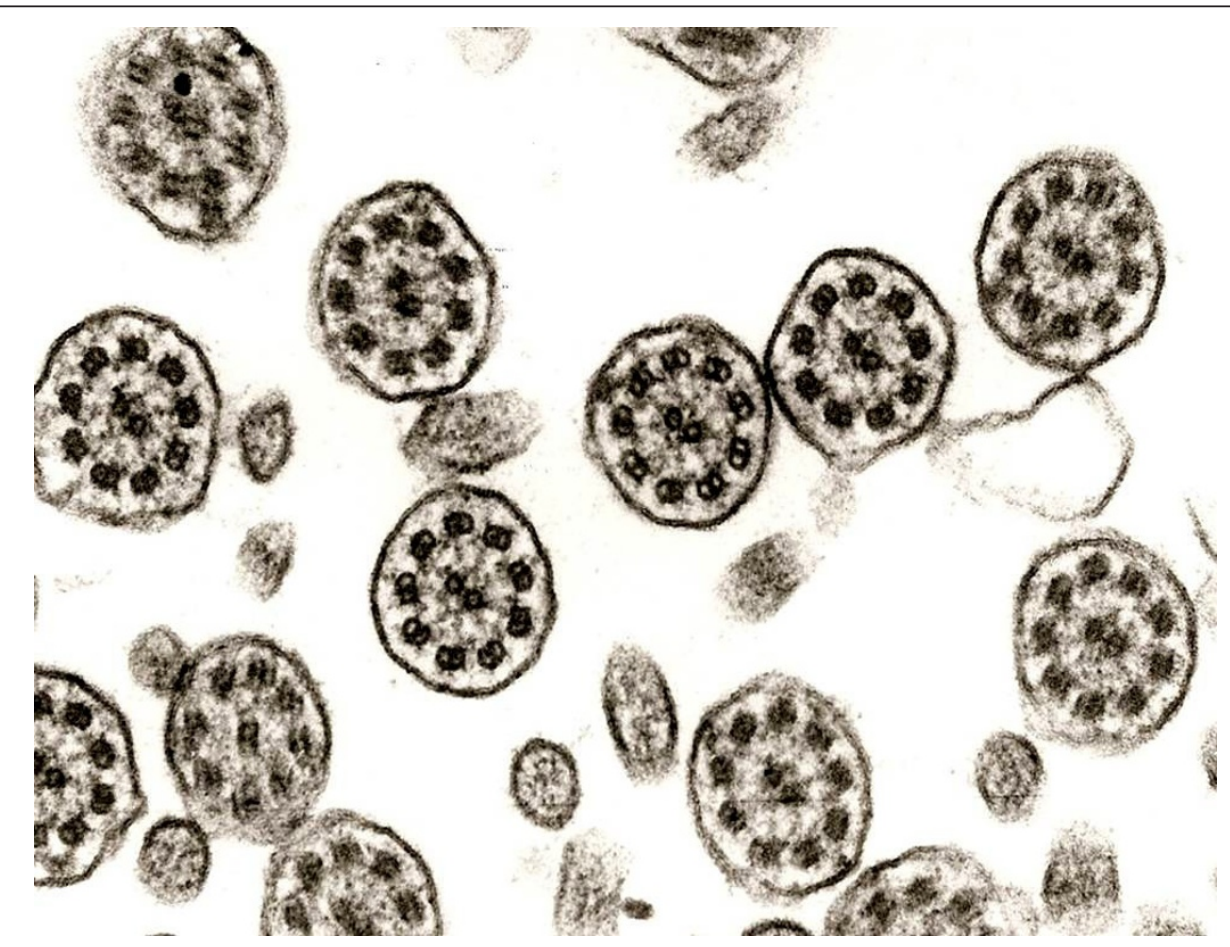

Figure 4 Defect of outer dynein arms. Isolated defect of outer dynein arms is only detected in some cases (original magnification $\times 85,000$ ). 
Table 2 Defects of dynein arms

\begin{tabular}{lll}
\hline Defect(s) of dynein arms & totally missing & rudimentary \\
\hline Inner dynein arms & $48(75.2 \%)$ & $16(24.8 \%)$ \\
Outer dynein arms & $4(66.6 \%)$ & $2(33.3 \%)$ \\
\hline
\end{tabular}

Defects vary from total loss to rudimentary structure.

with only a smaller number of cases dynein defects were not differentiated $[13,16]$. Main differences compared with other studies are found in the percentage of cases with defects of ODA and non-DA defects, which were relatively low in our study.

Disorientation of cilia can be found in PCD and was initially supposed to be a form of defect able to induce PCD [23]. Further studies support that these are secondary changes only [24].

Studies on ciliogenesis in cell culture are practised by Jorissen et al. [25], but do not seem to be a widely practised procedure. According to our experience computerassisted analysis is not necessary [26].
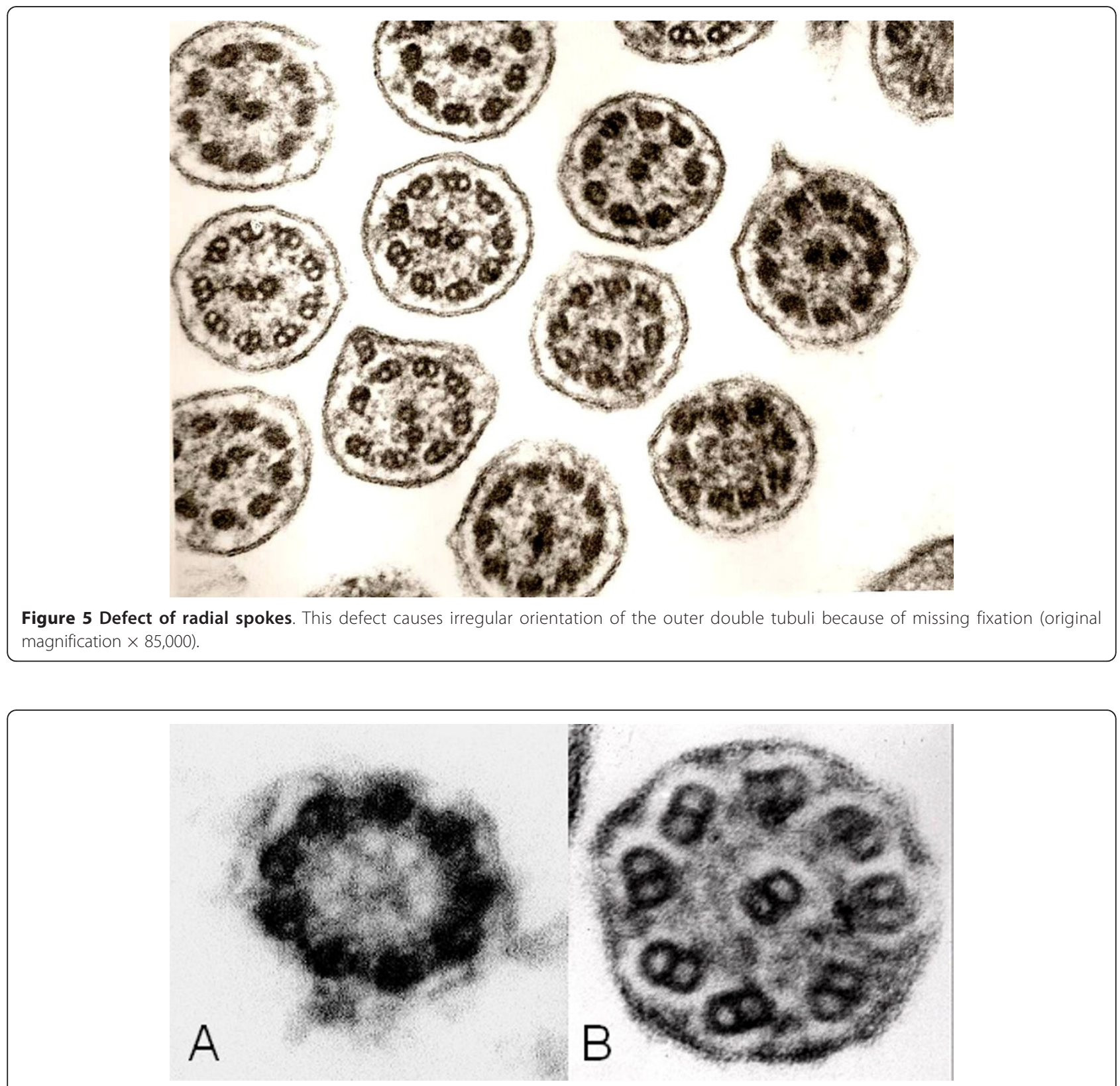

Figure 6 Single cilia view. In one case central tubuli were not found, dynein arms can not be evaluated in this picture (A, original magnification $\times 140,000)$. Combined defect with missing dynein arms and loss of outer double tubuli is seen ( $B$, original magnification $\times$ 140,000). 
Secondary changes of cilia are known in PCD, as a results of repeated infections and inflammation and sometimes also in healthy subjects [11]. Defects belonging to this category are plebs, loss of one outer membrane, compound cilia and numerical microtubular defects. In cases of severe secondary changes and infections repeated biopsies in an infect-free interval should be requested. In 16 (3.2\%) cases with only secondary changes in TEM analysis situs inversus, Kartagener Syndrome or dextrocardia were reported clinically. This is in accordance to other studies. Papon et al. [18] found 28 (5.2\%) patients with situs inversus in a group with normal ciliary ultrastrucure (total $=$ 533). In these cases we generally recommended analysis of ciliary beating frequency and pattern as well as repeated TEM investigation. Functional analysis should be done generally to detect cases with normal ultrastructure and to correlate results of both investigations [27]. Recently O'Callaghan et al. have demonstrated, that in cases with IDA defects in TEM analysis spontaneous restitution can occur. Therefore repeated testing is required [28]. Genetic analysis should be done, but does not cover all possible defects today [4]. Therefore PCD registers with all available information should be installed to push further knowledge. Quality control should be practised concerning functional and ultrastructural investigations.

\section{Conclusions}

Complete clinical information concerning history and results of functional analysis should be given to the pathologist. Brushings or biopsies not adequate for diagnostics should be repeated.

Functional and genetic analysis should be done as well to gather all available information.

PCD registers with all clinical, functional and pathological findings and biobanks should be installed to push further research.

\section{Additional material}

Additional file 1: Clinical and ultrastructural data of other larger studies. Explanations: S. inv./dex. = Situs inversus/dextrocardia,

${ }^{*}$ combined defects, ${ }^{* *}$ with ultrastructural defects, ${ }^{* * *}$ according to clinical information. table.

\section{Acknowledgements}

We thank all technicians of the TEM laboratories in the institutes in Bochum, Kiel and Essen for excellent assistance.

\footnotetext{
Author details

${ }^{1}$ Institute of Pathology and Neuropathology, University Hospital Essen, University of Duisburg-Essen, Hufelandstrasse 55, 45147 Essen, Germany. ${ }^{2}$ Institute of Pathology, MVZ Municipal Hospital, 24105 Kiel, Germany.
}

\section{Authors' contributions}

ME did all TEM analysis of the specimens in Bochum and Kiel, collected data from these patients and reviewed fotos from the specimens investigated in Essen. DTH did examinations of specimens in Essen, collected and analysed final data and wrote the manuscript. All authors provided fotos and revised the manuscript. All authors read and approved the final manuscript.

\section{Competing interests}

The authors declare that they have no competing interests.

Received: 9 August 2011 Accepted: 24 November 2011 Published: 24 November 2011

\section{References}

1. Badano JL, Mitsuma N, Beales PL, Katsanis N: The ciliopathies: an emerging class of human genetic disorders. Annu Rev Genomics Hum Genet 2006, 7:125-148.

2. Afzelius BA: A human syndrome caused by immotile cilia. Science 1976, 193(4250):317-319.

3. Ferkol T, Mitchison HM, O'Callaghan C, Leigh M, Carson J, Lie H, Rosenbluth D, Brody SL: Current issues in the basis mechanisms, pathophysiology, diagnosis and management of primary ciliary dyskinesia. Eur Respir Mon 2006, 37:291-313.

4. Barbato A, Frischer T, Kuehni CE, Snijders D, Azevedo I, Baktai G, Bartoloni L, Eber E, Escribano A, Haarman E, Hesselmar B, Hogg C, Jorissen M, Lucas J, Nielsen KG, O'Callaghan C, Omran H, Pohunek P, Strippoli MP, Bush A: Primary ciliary dyskinesia: a consensus statement on diagnostic and treatment approaches in children. Eur Respir J 2009, 34:1264-1276.

5. Bush A, Cole P, Hariri M, Mackay I, Phillips G, O'Callaghan C, Wilson R, Warner JO: Primary ciliary dyskinesia: diagnosis and standards of care. Eur Respir J 1998, 12:982-988.

6. Coren ME, Meeks M, Morrison I, Buchdahl RM, Bush A: Primary ciliary dyskinesia: age at diagnosis and symptom history. Acta Paediatr 2002, 91:667-669.

7. Bush A, Chodhari R, Collins N, Copeland F, Hall P, Harcourt J, Hariri M, Hogg C, Lucas J, Mitchison HM, O'Callaghan C, Phillips G: Primary ciliary dyskinesia: current state of the art. Arch Dis Child 2007, 92:1136-1140.

8. Lesic I, Maurer E, Strippoli MP, Kuehni CE, Barbato A, Frischer T: Primäre Ziliendyskinesie in Österreich. Wien Klin Wochenschr 2009, 121:616-622.

9. Popper H, Jakse R: Diagnose und Aspekte der Pathogenese des Kartagener-Syndromes an Hand von Nasenschleimhautbiopsien. Wien Klin Wochenschr 1982, 94:370-372.

10. Milara J, Armengot M, Mata M, Morcillo EJ, Cortijo J: Role of adenylate kinase type 7 expression on cilia motility: possible link in primary ciliary dyskinesia. Am J Rhinol Allergy 2010, 24:181-185.

11. de longh RU, Rutland J: Ciliary defects in healthy subjects, bronchiectasis, and primary ciliary dyskinesia. Am J Respir Crit Care Med 1995, 151:1559-1567.

12. Santamaria F, de Santi MM, Grillo G, Sarnelli P, Caterino M, Greco L: Ciliary motility at light microscopy: a screening technique for ciliary defects. Acta Paediatr 1999, 88:853-857.

13. Felix $H$, Holzmann D: Function and ultrastructure of cilia in primary ciliary dyskinesia. Schweiz Med Wochenschr 2000, 130:699-704.

14. Noone PG, Leigh MW, Sannuti A, Minnix SL, Carson JL, Hazucha M, Zariwala MA, Knowles MR: Primary ciliary dyskinesia: diagnostic and phenotypic features. Am J Respir Crit Care Med 2004, 169:459-467.

15. Carlén B, Stenram U: Primary ciliary dyskinesia: a review. Ultrastruct Pathol 2005, 29:217-220.

16. Plesec TP, Ruiz A, McMahon JT, Prayson RA: Ultrastructural abnormalities of respiratory cilia: a 25-year experience. Arch Pathol Lab Med 2008, 132:1786-1791.

17. Stannard WA, Chilvers MA, Rutman AR, Williams CD, O'Callaghan C: Diagnostic testing of patients suspected of primary ciliary dyskinesia. Am J Respir Crit Care Med 2010, 181:307-314.

18. Papon JF, Coste A, Roudot-Thoraval F, Boucherat M, Roger G, Tamalet A, Vojtek AM, Amselem S, Escudier E: A 20-year experience of electron microscopy in the diagnosis of primary ciliary dyskinesia. Eur Respir J 2010, 35:1057-1063.

19. Markmann HU, Matthus J: Das primäre ziliare Dyskinesiesyndrom. Ultrastrukturelle Beobachtungen bei einem Zwillingspaar. Pathologe 1990, 11:80-84. 
20. Theegarten D, Anhenn O, Hotzel H, Wagner M, Marra A, Stamatis G, Mogilevski G, Sachse K: A comparative ultrastructural and molecular biological study on Chlamydia psittaci infection in alpha-1 antitrypsin deficiency and non-alpha-1 antitrypsin deficiency emphysema versus lung tissue of patients with hamartochondroma. BMC Infect Dis 2004, 4:38.

21. Armengot M, Milara J, Mata M, Carda C, Cortijo J: Cilia motility and structure in primary and secondary ciliary dyskinesia. Am J Rhinol Allergy 2010, 24:175-180.

22. Sirvanci S, Seda Uyan Z, Ercan F, Karadag B, Ersu R, Karakoc F, Dagli E, San T: Quantitative analysis of ciliary ultrastructure in patients with primary ciliary dyskinesia. Acta Histochem 2008, 110:34-41.

23. Rayner CF, Rutman A, Dewar A, Greenstone MA, Cole PJ, Wilson R: Ciliary disorientation alone as a cause of primary ciliary dyskinesia syndrome. Am J Respir Crit Care Med 1996, 153:1123-1129.

24. Jorissen $\mathrm{M}$, Willems $\mathrm{T}$ : The secondary nature of ciliary (dis)orientation in secondary and primary ciliary dyskinesia. Acta Otolaryngol 2004, 124:527-531.

25. Jorissen M, Willems T, Van der Schueren B, Verbeken E, De Boeck K: Ultrastructural expression of primary ciliary dyskinesia after ciliogenesis in culture. Acta Otorhinolaryngol Belg 2000, 54:343-356.

26. Escudier E, Couprie M, Duriez B, Roudot-Thoraval F, Millepied MC, PrulièreEscabasse V, Labatte L, Coste A: Computer-assisted analysis helps detect inner dynein arm abnormalities. Am J Respir Crit Care Med 2002, 166:1257-1262.

27. Chilvers MA, Rutman A, O'Callaghan C: Ciliary beat pattern is associated with specific ultrastructural defects in primary ciliary dyskinesia. J Allergy Clin Immunol 2003, 112:518-524.

28. O'Callaghan C, Rutman A, Williams GM, Hirst RA: Inner dynein arm defects causing Primary Ciliary Dyskinesia: Repeat testing required. Eur Respir J 2011, 38:603-607.

doi:10.1186/1746-1596-6-115

Cite this article as: Theegarten and Ebsen: Ultrastructural pathology of primary ciliary dyskinesia: report about 125 cases in Germany.

Diagnostic Pathology 2011 6:115.

\section{Submit your next manuscript to BioMed Central and take full advantage of:}

- Convenient online submission

- Thorough peer review

- No space constraints or color figure charges

- Immediate publication on acceptance

- Inclusion in PubMed, CAS, Scopus and Google Scholar

- Research which is freely available for redistribution

Submit your manuscript at www.biomedcentral.com/submit 